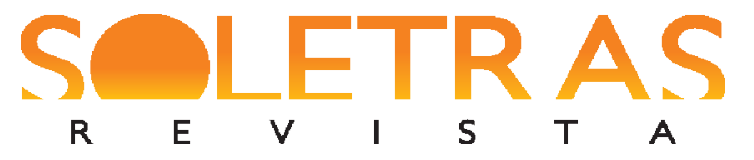

\title{
Entrevista Especial
}

Luiz Amaral ${ }^{1}$

University of Massachusetts-Amherst

\section{Entrevista concedida aos professores Kátia Abreu e Eduardo Kenedy}

Soletras: Na sua visão da área, como os estudos de aquisição bilíngue podem ser pensados no campo da formação de professores?

Temos no Brasil um caso muito peculiar. Enquanto o bilinguismo faz parte da realidade cotidiana na maior parte dos países do mundo, no Brasil o monolinguismo predomina de forma bastante clara. O Brasil é o maior país monolíngue do mundo. Tanto Rússia como China, Estados Unidos e Canadá apresentam muito mais situações de multilinguismo em diferentes áreas de seus respectivos territórios. No Brasil, nem em zonas de fronteira encontramos muitos brasileiros falando espanhol, inglês ou francês. Normalmente vemos o oposto, as populações de fronteira dos países vizinhos acabam aprendendo o português para se comunicar conosco. Com exceção de algumas pequenas comunidades bilíngues na região Sul e as comunidades indígenas que conseguem manter suas línguas, é muito difícil encontrar em nosso cotidiano áreas onde outras línguas sejam faladas. Isso leva a um grau de isolamento linguístico que gera uma noção distorcida por parte da sociedade com relação à habilidade humana de lidar com mais de uma língua ao mesmo tempo. O ser humano é biologicamente programado para ser bilíngue. A pesquisa em bilingüismo, tanto na Europa quanto na América do Norte, comprova os ganhos associados ao bilinguismo do ponto de vista pessoal, social e até mesmo da saúde mental.

Em geral, os estudos sobre bilinguismo podem ajudar na formação de professores de duas maneiras. Para professores de língua estrangeira, esses estudos são fundamentais para que os profissionais entendam como a mente humana lida com múltiplas línguas e como podemos facilitar o processo de aprendizado dessas línguas. Podemos encontrar várias aplicações para a sala de aula, com dinâmicas, abordagens ou métodos motivados por

1 Professor associado de Linguística Hispânica na Universidade de Massachusetts Amherst (UMASS); e trabalha com Aquisição de Segunda Língua e Bilinguismo, Linguística Aplicada e Línguas Nativas da América Latina. Tem interesse em interfaces possíveis entre aquisição de língua, educação bilíngue e documentação, revitalização e manutenção de línguas nativas. Seus projetos de pesquisa lidam com populações bilíngues nos Estados Unidos, México e Brasil. Codiretor do Language Acquisition Research Center da Universidade de Massachusetts. $\underline{\text { amaral@ } \text { spanport.umass.edu }}$ 


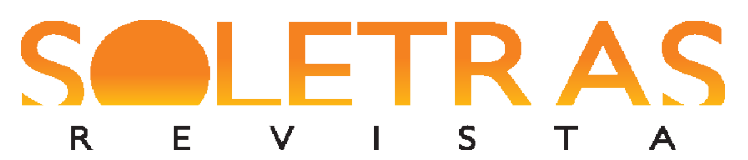

N. 33 ï 2017.1 ï LUIZ AMARAL

diferentes estudos sobre a mente bilíngue. Por exemplo, se entendemos os mecanismos que um falante bilíngue usa para armazenar informações lexicais e os tipos de problemas com a interferência entre o léxico de duas ou mais línguas, podemos desenvolver e ensinar estratégias para lidar com a chamada transferência lexical negativa. Vale ressaltar aqui que desde as décadas de 80 e 90 a noção de bilíngue tem se ampliado para incluir tanto falantes adultos de segunda língua (bilíngue sequencial tardio) como crianças que nascem em ambientes bilíngues (bilíngue simultâneo de primeira infância), além de todos os outros casos entre esses dois extremos onde o falante usa duas línguas.

Já no caso dos professores de português como língua materna, uma maior compreensão sobre a mente bilíngue pode ajudar o profissional a refletir sobre questões cognitivas relacionadas à diglossia e à variação dialetal. Nos Estados Unidos já existe um conjunto significativo de estudos sobre o impacto das diferentes variantes do inglês sobre os processos educacionais, incluindo estudos sobre o inglês afro-americano e o famoso Spanglish (que mistura traços do inglês e do espanhol). No Brasil, temos que avançar em nossas pesquisas com falantes de diferentes dialetos para melhor descrever a representação e o processamento de diferentes propriedades gramaticais em casos de variações dialetais. Essas diferenças tanto de vocabulário como de propriedades formais da gramática podem interferir em processos de aprendizagem, como no letramento pleno, por exemplo.

Soletras: Considerando seu trabalho na UMASS e no Brasil e levando em conta a perspectiva de uma época que exige cada vez mais um fazer científico voltado para fora dos muros da Universidade, que contribuições os estudos que integram Psicolinguística e Educação poderiam trazer?

Eu acredito muito nos possíveis ganhos que o diálogo entre a linguística em geral (incluindo a Psicolinguística) e outras áreas de conhecimento pode trazer para aplicações relacionadas à educação; desde o desenvolvimento de softwares educacionais até a criação de novas abordagens de ensino e de materiais didáticos mais adequados às necessidades de professores e alunos. Uma boa parte do meu trabalho mais recente tem sido dedicada justamente a estabelecer mecanismos de diálogo para possibilitar a construção de experiências que facilitem essa troca de informações e de perspectivas sobre a natureza da linguagem humana e os processos de aprendizado. O problema é que muitas vezes nossas instituições 


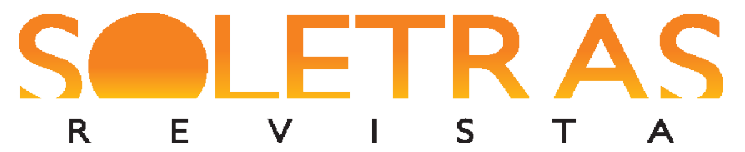

N. 33 ï 2017.1 ï LUIZ AMARAL

(tanto locais como nacionais) criam regras e práticas que dificultam essas parcerias. Esse é um outro tema bastante complicado, que não vou tratar aqui nesse espaço.

Mais além dos entraves institucionais, para que as parcerias sejam frutíferas, é necessário que os diferentes interlocutores estejam verdadeiramente interessados nas perspectivas e na contribuição de seus parceiros. Muitas iniciativas morrem logo no início porque os diferentes lados envolvidos estão mais preocupados em convencer os demais membros da equipe da importância do seu conhecimento em sua área específica de atuação, do que buscar possíveis aplicações às contribuições dos demais interlocutores.

Recentemente eu participei de uma experiência bastante interessante durante uma oficina do projeto Saberes Indígenas na UFMG. A convite dos professores da Faculdade de Educação da UFMG que trabalham com educação indígena e do Instituto Socioambiental, reunimos vários linguistas, antropólogos, educadores e professores de língua para preparar uma proposta de um material de alfabetização para quatro línguas nativas brasileiras. Cada um dos grupos expôs seus temas de interesse e possíveis contribuições para ajudar no design final do material. Os linguistas falaram sobre as representações fonéticas dos grafemas e sobre os processos de aprendizado baseados em métodos fonológicos. Os educadores apresentaram várias considerações sobre a necessidade de se trabalhar a noção de texto desde as primeiras lições para que os futuros leitores entendam os objetivos do processo de letramento. Os antropólogos discutiram temas relacionados a inserção da língua escrita nas comunidades indígenas e como os diferentes processos afetam o aprendizado e o uso de uma modalidade linguística que até pouco tempo não era considerada pela comunidade. Por fim, os professores indígenas apresentaram os desafios e os objetivos no uso do material proposto. Ao final de uma semana, conseguimos formalizar uma proposta para o livro de alfabetização que levava em consideração as diferentes perspectivas sobre os objetivos do material, a natureza do processo de aprendizado e as possíveis abordagens de ensino. A contribuição de cada uma das partes foi fundamental para que pudéssemos encarar o desafio de produzir um material de alfabetização para línguas sem grandes tradições escritas de forma mais coerente dos pontos de vista linguístico, educacional e antropológico. A partir dessa experiência, eu desenvolvi uma parceria com a professora e antropóloga Ana Maria Gomes, da Universidade Federal de Minas Gerais (UFMG), que tem me ajudado a pensar de forma mais ampla e balizada os processos antropológicos de inserção da língua escrita em comunidades indígenas. Tenho 


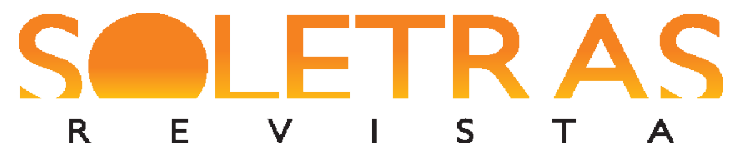

N. 33 ï 2017.1 ï LUIZ AMARAL

aprendido bastante com essa parceria e tenho certeza de que a nossa interlocução tem gerado frutos para ambas as partes.

Com relação à psicolinguística e à educação, acredito que exista uma possibilidade quase que infinita de trocas de experiências e conhecimento técnico. Porém, é muito importante que os psicolinguistas não tentem reduzir os processos de aprendizado a questões técnicas de processamento da linguagem. Existem muitos fatores que afetam o aprendizado formal da língua, desde questões cognitivas até situações sociais, psicológicas e de natureza pessoal. Alguns dos grandes problemas de desempenho das escolas brasileiras estão simplesmente relacionados à violência, à fome ou ao estigma social. Eu sempre digo que o trabalho que eu desenvolvo com professores indígenas para produzir material didático seria completamente inviável se os educadores e as lideranças locais não tivessem chegado 20 anos antes e transformado completamente o papel da escola indígena nas diferentes comunidades. Por outro lado, é fundamental que os educadores também estejam abertos a discutir questões técnicas sobre a natureza e o processamento da linguagem. Nem todo conhecimento específico de cada uma das áreas será útil o tempo todo para que esse diálogo seja frutífero. É importante que cada profissional saiba buscar dentro de seu conhecimento teórico os temas que podem facilitar o diálogo e contribuir para ações conjuntas.

Soletras: Que trabalhos você destacaria para os estudantes da área de Estudos da Linguagem como inspiradores dentro do campo da Psicolinguística e Educação?

Primeiramente, é importante lembrar que essas são duas áreas distintas com seus temas e objetivos de pesquisa bastante diferentes. É essencial para projetos de colaboração que ambas as partes possam compreender e respeitar essas diferenças. Meu conselho para estudantes que queiram explorar a interface entre a psicolinguística e a educação é a de que não comecem a estudar esse tema a partir da interface. Escolham uma dessas áreas e construam um conhecimento sólido da literatura especializada na área escolhida. Ou seja, primeiro é necessário conhecer os grandes nomes em Educação ou em Psicolinguística para depois se pensar no diálogo entre as duas. Comecem com Paulo Freire ou Noam Chomsky, por exemplo, e construam uma bibliografia especializada em cada área. Em seguida, procurem interlocutores sérios com a mesma formação sólida na área com a qual queiram estabelecer a parceria e busquem se informar sobre as possíveis áreas de interface. Eu acredito 


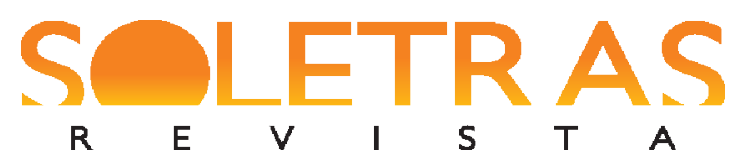

N. 33 ï 2017.1 ï LUIZ AMARAL

muito no trabalho multidisciplinar, porém é necessário ter o conhecimento técnico suficiente em cada uma das disciplinas envolvidas. A boa notícia é que temos no Brasil excelentes cursos com pesquisadores reconhecidos internacionalmente em ambas as áreas, o que permite aos estudantes buscar a literatura de base para obter uma formação sólida.

Soletras: Qual o estado de suas pesquisas atuais a respeito da revitalização de línguas ameaçadas de extinção?

Durante algum tempo eu mantive de forma relativamente separada a minha pesquisa teórica com falantes bilíngues de línguas indígenas das minhas atividades aplicadas de apoio a projetos de manutenção e revitalização de línguas latino-americanas. Não que eu ache que esses dois tipos de atividade têm que estar separados, mas simplesmente porque as exigências de trabalhos aplicados e de pesquisas acadêmicas podem ser bastante distintas e às vezes fazem com que seja mais fácil dissociar projetos de diferentes naturezas. Há mais ou menos dois anos, durante uma visita a comunidades zapotecas na Sierra Norte, do Estado de Oaxaca, no México, percebi que havia uma real necessidade nas escolas locais de estudos com testagem bilíngue para apoiar projetos de ensino de língua. Essa realidade é mais ou menos evidente para todos os que desenvolvem atividades de apoio ao ensino de línguas indígenas. Você chega a uma comunidade e os professores da escola começam a narrar o problema da falta de material para o ensino da língua indígena. O problema é que raramente alguém sabe dar uma informação precisa sobre o conhecimento linguístico dos alunos que estão em sala de aula. Qualquer pessoa que trabalhe com o desenvolvimento de material didático para o ensino de língua sabe que dependendo do conhecimento linguístico do aprendiz, o material a ser desenvolvido vai ser bastante diferente. Um livro de alfabetização só serve para quem já fala a língua. No Brasil, apesar de existirem várias exceções, muitas comunidades indígenas ainda estão bastante isoladas do ponto de vista linguístico, o que faz com que seja mais fácil prever o tipo de material adequado. No México, quase nenhuma comunidade tem esse tipo de isolamento. Foi então que eu decidi, junto com a Ana Alonso, minha orientanda de doutorado, que é falante nativa de zapoteco, desenvolver um projeto de testagem bilíngue para verificar a proficiência linguística de crianças zapotecas do ensino fundamental e contribuir para estudos de transmissão intergeracional usando uma metodologia experimental, ao invés de uma metodologia mais tradicional baseada em questionários sociolinguísticos. Já fizemos duas testagens piloto para desenvolver um teste de vocabulário para crianças e estamos na primeira 


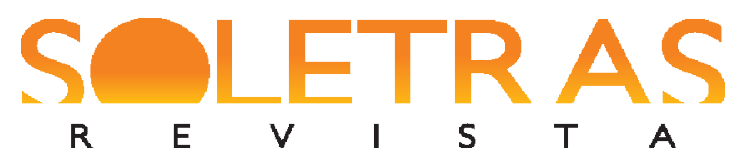

N. 33 ï 2017.1 ï LUIZ AMARAL

versão de uma sequência de experimentos de aquisição com três áreas da gramática zapoteca: (i) marcadores aspectuais, (ii) ordem de constituintes em orações com diferentes tipos verbo, e (iii) aquisição de tons.

Como essa realidade também existe no Brasil, estou coorientando a tese de mestrado, na Universidade Federal de Roraima (UFRR), de uma aluna Wapichana chamada Wendy Leandro, com quem já escrevi dois artigos sobre aquisição bilíngue. Estamos desenvolvendo um teste de vocabulário para dar o pontapé inicial a criação de mecanismos de testagem bilíngue para crianças Wapichana, em idade escolar. Em um segundo momento, após os procedimentos de validação dos instrumentos gerados, estamos pensando na possibilidade de um estudo de mapeamento sobre a transmissão intergeracional do Wapichana na região da Serra da Lua em Roraima. Esses dois estudos, tanto no Brasil como no México, são de certa forma pioneiros porque usam certas metodologias já consagradas em áreas de testagem bilíngue para verificar a vitalidade linguística entre crianças e jovens que vivem em comunidades indígenas com grande exposição às línguas nacionais (espanhol ou português).

Esse ano comecei também a trabalhar com uma outra aluna de doutorado, chamada Isaura de los Santos, que é falante de Chatino (outra língua otomangue mexicana), em um projeto que visa propor uma metodologia de alfabetização para uma língua com 8 tons onde as palavras monossilábicas são a norma. É um desafio bastante interessante, que mistura estudos de descrição e tipologia linguística, teorias de alfabetização, aprendizado de línguas e práticas de desenvolvimento e testagem de material didático.

Soletras: Você é um pesquisador que conjuga diversas áreas de interesse, como a teoria das múltiplas gramáticas, a HPSG, o modelo DAI, a revitalização de línguas, gramáticas pedagógicas, dentre outros domínios do conhecimento. Na sua interpretação, esses saberes encontram-se relacionados no dia a dia de seu trabalho com as línguas naturais?

Eu às vezes acho que os meus trabalhos advêm de áreas diversificadas, tanto teóricas como aplicadas, de aquisição e ensino de língua e são diretamente motivados por uma frustração natural de pesquisador. A gente está sempre buscando modelos e práticas mais abrangentes, generalizáveis e acaba se deparando com as dificuldades inerentes a realidades específicas e particulares. Eu adoro todas as minhas áreas atuação, mas acredito estar consciente de suas limitações individuais. Por exemplo, modelos de aquisição e processamento de línguas naturais são fundamentais para explicar a natureza da linguagem. 


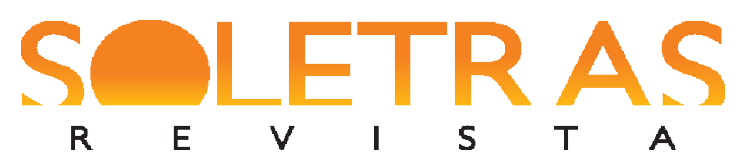

N. 33 ï 2017.1 ï LUIZ AMARAL

Eles nos ajudam a entender algo essencial sobre a mente humana e seu funcionamento. De certa forma, são socialmente importantes porque apontam o que há de comum entre todos os indivíduos de nossa espécie. Porém, é impossível explicar todas nossas ações e práticas linguísticas com esses modelos. Na verdade, não é nem desejável. A perspectiva gerativista que tem como objetivo explicar o que há de comum entre o desenvolvimento linguístico de todos os seres humanos perde sua força se tentamos encaixá-la em um quadro onde é importante explicar as diferenças de performance relacionadas à compreensão de um texto, por exemplo. A questão é sempre como conciliar essas diferentes perspectivas sobre a natureza da linguagem e os processos de aprendizagem.

A maneira que eu encontrei para encarar esse dilema e lidar com essa frustração é compreender as propriedades básicas e as limitações dos modelos científicos usados. Se algum dia você tiver a oportunidade de visitar a exposição permanente do Museu de Ciências de Boston (um dos meus museus preferidos), vá diretamente a parte que explica o que são modelos científicos e os ilustra com maquetes, desenhos e quadros sobre insetos, vulcões, rios, etc. Os modelos são representações de processos, ideias ou objetos que não podem ser experimentados diretamente. Eles são fundamentais porque nos permitem analisar essas realidades que seriam inatingíveis de outra maneira. $\mathrm{O}$ que não podemos nos esquecer é que eles não são a realidade em si, por isso são limitados aos elementos observáveis que queremos ou conseguimos descrever. Logo, são extremamente influenciados por nosso ponto de vista e nossas tradições científicas. Uma maquete de um vulcão pode me ajudar a testar e prever a pressão dos gases dentro de vulcões reais, mas essa maquete não é um vulcão de verdade.

Os modelos linguísticos não são diferentes de outros modelos científicos. Com um objeto de investigação tão poderoso, complexo e abstrato como a linguagem humana, não é de se estranhar que diferentes modelos enfatizem diferentes propriedades do sistema e que cada um tenha vantagens e limitações em relação aos demais. Por isso, eu não consigo me limitar a uma perspectiva ou teoria quando estudo a linguagem humana. Eu normalmente acho todas as áreas e todas as ideias muito interessantes. Acho que além da curiosidade natural por qualquer informação relacionada à linguagem, eu também tive a oportunidade de conviver com grandes estudiosos de diferentes formações acadêmicas. Eu fiz minha graduação em letras na Universidade do Estado do Rio de Janeiro (UERJ), na primeira metade dos anos 90, e tive o enorme privilégio de ter feito dois cursos de filologia românica com o professor Evanildo Bechara. Durante meu mestrado na Pontifícia Universidade Católica (PUC-Rio), fiz cursos 


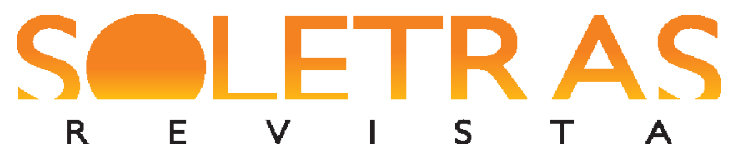

N. 33 ï 2017.1 ï LUIZ AMARAL

muito interessantes em diferentes áreas da linguística com professores como Margarida Basílio, Letícia Sicuro Corrêa, Mariza Pimenta-Bueno, Helena Martins, Carmelita Dias e Violeta Quental, que foi a minha orientadora. Já no doutorado, na Ohio State University, estudei sintaxe com Peter Culicover, Bob Levine e Carl Pollard e semântica com David Dowty e Javier Rexach, pragmática com Craige Roberts e Scott Schwenter e linguística computacional com Chris Brew e Detmar Meurers, que foi meu orientador. Confesso que até hoje me pergunto por que escrevi uma tese sobre sistemas de processamento automático de línguas para o ensino de L2. Poderia ter me dedicado mais à sintaxe teórica ou a vários outros campos da linguística. Hoje em dia, continuo aprendendo e dialogando com colegas excepcionais tanto no Brasil como nos Estados Unidos. Chama-me sempre muita atenção o caso de pesquisadores que conjugam interesses em diferentes áreas de atuação. No Brasil, por exemplo, acompanho de perto pesquisadores como Marcus Maia, da Universidade Federal do Rio de Janeiro (UFRJ), que desenvolve um trabalho de altíssima qualidade e igual desenvoltura em áreas tão distintas como processamento da linguagem e descrição de línguas indígenas, ou Ricardo de Souza, da Universidade Federal de Minas Gerais (UFMG), que além de um excelente trabalho em processamento de L2 também tem uma formação extensa em áreas de linguística aplicada que dialogam diretamente com o meu trabalho como pesquisador.

Em suma, eu vejo de forma bastante positiva os pesquisadores de Estudos da Linguagem que querem se desfazer das amarras de teorias específicas e desejam explorar com seriedade diferentes modelos linguísticos e dialogar com outras disciplinas, seja para desenvolver projetos aplicados ou avançar o nosso conhecimento sobre a cognição humana. É importante deixar claro que eu não acredito em pessoas que se tornam especialistas em tudo. Minha perspectiva é muito mais de eterno aprendiz que de professor onisciente. Durante toda a minha carreira eu sempre me considerei um estudante. $\mathrm{O}$ que eu procuro tanto em parceiros de pesquisa quanto em estudantes de doutorado são pessoas sérias que queiram se dedicar a temas específicos e possivelmente aplicar esse conhecimento a problemas existentes fora do mundo acadêmico. A qualidade dos projetos multidisciplinares só pode ser alcançada com uma fundamentação sólida nas diferentes disciplinas envolvidas.

Entrevista realizada em 12 de junho de 2017. 